\title{
In vitro Study of Secreted Aspartyl Proteinases Sap1 to Sap3 and Sap4 to Sap6 Expression in Candida albicans Pleomorphic Forms
}

\author{
MONIKA STANISZEWSKA ${ }^{1}$, MAEGORZATA BONDARYK ${ }^{1}$, KATARZYNA SIENNICKA², ANNA KUREK ${ }^{3}$, \\ JACEK ORŁOWSKI ${ }^{4}$, MARTIN SCHALLER ${ }^{4}$ and WIESŁAW KURZĄTKOWSKI ${ }^{1}$ \\ ${ }^{1}$ Independent Laboratory of Streptomyces and Fungi Imperfecti, \\ National Institute of Public Health-National Institute of Hygiene, Warsaw, Poland \\ ${ }^{2}$ Warsaw University of Life Science, Warsaw, Poland \\ ${ }^{3}$ Department of Bacterial Genetics, Institute of Microbiology, University of Warsaw, Warsaw, Poland \\ ${ }^{4}$ Laboratory of Fungal Glycobiology, Institute of Biochemistry and Biophysics, \\ Polish Academy of Sciences, Warsaw, Poland \\ ${ }^{4}$ Department of Dermatology, Eberhard-Karls-University Tübingen, Tübingen, Germany
}

Received 13 January 2012, revised 20 August 2012, accepted 1 September 2012

\section{Abstract}

Transition from round budding cells to long hyphal forms and production of secreted aspartic proteases (Saps) are considered virulenceassociated factors of Candida albicans. Although plenty of data dealing with Saps involvement in the infection process have been published, Saps expression by the different pleomorphic forms as well as the capacity of C. albicans filaments to express Sap1-6 under serum influence are poorly investigated. In this study, we used immunofluorescence and immunoelectron microscopy for the detection of Sap1-6 isoenzymes in C. albicans pleomorphic cells (blastoconidia, germ tubes, pseudohyphae, true hyphae) grown in Sap-inductive human serum and Sap non-inductive medium - yeast extract-peptone-glucose (YEPD). Isoenzymes were below the detection level in all blastoconidial cells grown in YEPD for $18 \mathrm{~h}$. Sap1-6 expression was hardly detected in C. albicans cells cultivated in serum for 20 min. Increasing level of Sap 1-6 expression was observed when C. albicans was incubated for 2, 6 and $18 \mathrm{~h}$ in serum corresponding to the development of germ tubes, pseudohyphae and true hyphae. The expression of Sap1-3 in pseudohyphae and true hyphae was more intensive compared to Sap4-6. Thus, we could show that human serum induced hyphae formation and the expression of Sap1-6 were co-regulated.

Key word s: Candida albicans, aspartic protease expression, isoenzymes 1-3, isoenzymes 4-6, morphotypes

\section{Introduction}

The opportunistic fungal pathogen Candida albicans possesses a repertoire of virulence attributes including adhesion to host tissue, the ability to undergo reversible morphogenetic transition, the secretion of extracellular hydrolases, and rapid switching between different phenotypic forms (Argimón et al., 2007; Naglik et al., 2008; Dalle et al., 2010; Hayek et al., 2010). Among the hydrolytic enzymes, aspartic proteases (Saps) are considered to be key virulence determinants of C. albicans which contribute to the adhesive and invasion capabilities of strains from this species (Raška et al., 2007; Tongchusak et al., 2008; Dalle et al., 2010). Saps are the products of a family of 10 SAP genes divided into subfamilies based on amino acid sequence homology alignment (SAP1 to SAP3, SAP4 to SAP6, SAP9, and SAP10). Further- more, SAP7 and SAP8 are divergent and are not represented as subfamily members (Hube et al., 1994; Monod et al., 1994 and 1998; Chen et al., 2002; Correia et al., 2010). Expression of the SAP genes varies according to the type and stage of the disease (Schaller et al., 2001; Fradin et al., 2003; Taylor et al., 2005; Jackson et al., 2007; Correia et al., 2010; Naglik et al., 2008; Abegg et al., 2011). Moreover, SAP genes expression is also regulated during the morphological transition (Argimón et al., 2007; Décanis et al., 2011). Candida albicans is able to grow in different forms (blastoconidia, germ tubes, pseudohyphae and true hyphae), a phenomenon defined as pleomorphism (Whiteway and Bachewich, 2007). Pleomorphic forms enable C. albicans to colonize and invade human tissues (Morrison et al., 2003; Kumamoto and Vinces, 2005a; 2005b; Raška et al., 2007; Barnett, 2008). It was found (Gow et al., 2002) that the

\footnotetext{
* Corresponding author: M. Staniszewska, Independent Laboratory of Streptomyces and Fungi Imperfecti, Chocimska 24, 00791,
} Warsaw, Poland; phone: +48 5421 228; fax: +48 228497 484; e-mail: m.staniszewska@pzh.gov.pl 
morphogenetic response (transition from budding to hyphal cells) of C. albicans as well as expression of SAP genes are triggered by factors existing in the environment of the host ( $\mathrm{pH}$, temperature, serum).

Previous studies (Schaller et al., 2000; Felk et al., 2002; Naglik et al., 2003; 2008; Lermann and Morschhäuser, 2008; Gropp et al., 2009; Dalle et al., 2010), indicate that the expression of Sap isoenzymes, for the morphogenesis of C. albicans varies strongly, depending on the experimental setup having a significant impact on the dependence on protease activity. Felk et al. (2002) showed that in vivo (in tissue from infected mice) expression of Sap1-3 was detected on the surface of both yeast and hyphal of wild-type cells. In contrast, the Sap4-6 antigens were identified mostly on penetrating hyphal cells (Schaller et al., 2000; 2001; Copping et al., 2005; Hornbach et al., 2009). Those authors suggested that Sap4-6 are the hyphal-associated proteins which is in striking contrast to the results obtained by Lermann and Morschhäuser (2008), who suggested that none of the SAP1-6 genes is required for invasion of vaginal RHE by hyphal morphologies. Moreover, according to Correia et al. (2010) Sap1-6 do not play a significant role in C.albicans virulence in a murine model of hematogenously disseminated candidiasis and that, in this model, Sap1-3 are not necessary for successful C. albicans infection.

In contrast, previous reports (Naglik et al., 1999; Schaller et al., 2000; Hube, 2004; Hornbach et al., 2009) showed that the Sap4-6 subfamily produced in high level by hyphal cells plays a role in immune evasion and protection from phagocytic killing by murine macrophages. Gropp et al. (2009) showed that Sap1-3 degrade and inactivate the central human complement components C3b, C4b as well as C5 and block the damaging effects of the activated complement system.

Although plenty of data dealing with the Saps involved in the infection process have been published the expression of Saps in particular morphotype is not sufficiently described. Given the role of serum in hyphae formation (Lermann and Morschhäuser, 2008; Gropp et al., 2009) and as SAP1-3 play essential role in the growth of C.albicans in medium consisting proteins (Felk et al., 2002; Lermann and Morschhäuser, 2008; Naglik et al., 2008; Gropp et al., 2009) as well as SAP4-6 are hypha-related genes (Lermann and Morschhäuser,
2008; Naglik et al. 2008; Gropp et al., 2009), we asked whether Sap1-3 or Sap4-6 are expressed in each morphotype under human serum influence in vitro. In addition, we analyzed whether any differences in expression between these two subfamilies exist. To investigate the expression of the Sap1-3 and Sap4-6 proteins, we studied the media, $\mathrm{pH}$, and temperature shifts. Following to previous conclusion (Hube et al., 1994; Naglik et al., 1999; Wise et al., 2007; Gropp et al., 2009), that different expression profiles of Saps are regulated by $\mathrm{pH}$ of the maintenance medium, we studied $\mathrm{pH}$, and temperature shifts during expression of the Sap1-3 and Sap4-6. In contrast to all other members of the Sap family, the proteases Sap9-10 monitored under conditions in vitro and in vivo are independent of $\mathrm{pH}$ and morphotype (Hornbach et al., 2009; Schild et al., 2011). Moreover, the expressions of Sap7 and Sap8 do not correlate with virulence (Hornbach et al., 2009). That is why we did not include Sap7, Sap8, Sap9 and Sap10 respectively in our study.

The aim of this study was to: (i) examine the expression of aspartic proteases (Sap1 to Sap3 and Sap4 to Sap6) in vitro in neutral $\mathrm{pH}$ during morphogenesis under human serum influence by immunofluorescence and immunoelectron microscopy; (II) establish the relationship between isoenzymes expression and pleomorphism; (iii) determine the localization of Sap1-3 and Sap4-6 in pleomorphic cells of C. albicans by immunoelectron microscopy.

\section{Experimental}

Materials and Methods

Strains and growth conditions. The Candida strains used in this study are listed in Table I. The clinical isolate of C.albicans (strain 82) was recovered from the blood of 3-year-old patient being treated for an anaplastic ependymoma. In the study, we used ATCC SC5314 reference strain to analyse the conceivable differences in Sap1-3 and Sap4-6 expression profile appearing between pleomorphic forms and various C.albicans strains. The stock culture of examined strains was stored on ceramic beads (Microbank ${ }^{\mathrm{TM}}$, Pro-Lab Diagnostics, Canada) at $-70^{\circ} \mathrm{C}$. Prior to the respective examinations,

Table I

Candida strains used in this study

\begin{tabular}{|l|c|c|l|}
\hline \multicolumn{1}{|c|}{ Designation } & Clone or strain & $\begin{array}{c}\text { Relevant characteristics } \\
\text { or genotype }\end{array}$ & \multicolumn{1}{|c|}{ Reference } \\
\hline Wild type, clinical isolate & 82 & URA3/URA3 & Staniszewska et al. (2011a) \\
\hline Wild type, reference strain & ATCC 5314 & URA3/URA3 & Gillum et al. (1984) \\
\hline Wild type, reference strain & ATCC MYA 581 & URA3/URA3 & Sullivan et al. (1995) \\
\hline
\end{tabular}


routine culturing of strains for growth was conducted at $30^{\circ} \mathrm{C}$ for $18 \mathrm{~h}$ in extract-peptone-glucose broth medium YEPD [10 g yeast extract, 20 g peptone (BBL Trypticase Peptone, Becton Dickinson) and 20 g glucose, pH 5.7] (Ness et al., 2010).

Phenotypic and biochemical characterization. The presumptive identification of the clinical strain 82 was conducted using CHROMagar Candida medium (Becton Dickenson, Sparks, MD, USA), as described previously Staniszewska et al. (2011b). Colors of the colonies were compared in reference to the C. albicans SC5314 strain. The assimilation pattern of the isolate and the reference strains SC5314 was determined using the API 20C AUX identification system (BioMérieux, France). The API 20C AUX test was used according to the manufacturer's instructions. Results of the test were obtained based on the numerical profile read-out (Analytical Profile Index; BioMérieux) (Staniszewska et al., 2011a).

Molecular examination. DNA was extracted from blastoconidial cells of the clinical isolate as well as C. dubliniensis ATCC MYA 581 and C. albicans SC 5314 according to Yeast DNA Miniprep Protocol as described by Amberg and Burke (2005), and DNA quantification was performed using the NanoDrop ND 1000 spectrophotometer at an absorbance of $260 \mathrm{~nm}$. Ribosomal DNA region including a fragment of the 5.8S rDNA gene (GenBank) was amplified by standard PCR. The primers (CALB1, CALB2) were used for species-specific PCR (Luo and Mitchell, 2002). The species-specific PCR products were electrophoresed as previously described Luo and Mitchell (2002). DNA bands were visualized using a transilluminator SYNGENE (Division of Synoptics LTD) under UV $260 \mathrm{~nm}$. Results were documented by using the GenSnap program.

In vitro study of aspartic protease enzyme expression. The expression of Sap isoenzymes in C.albicans strain cultivated in YEPD medium and, subsequently, in filtered undiluted human serum was studied. Expression of Sap1-3 and Sap4-6 was monitored in blastoconidial cells, germ tubes, pseudohyphal and true hyphal forms.

Induction of pleomorphic cells. Blastoconidial cells were grown as described Staniszewska et al. (2011a). Cells were observed under a phase-contrast microscope (Docuval, Carl Zeiss, Germany). Then, blastoconidia were harvested, washed three times with distilled water, pelleted by centrifugation ( $300 \mathrm{~g}$ for $10 \mathrm{~min}$ ), and stored at $-70^{\circ} \mathrm{C}$ for $96 \mathrm{~h}$.

To induce remaining pleomorphic forms the blastoconidial cells suspensions in YEPD $(50 \mu \mathrm{l})$ were transferred to $500 \mu \mathrm{l}$ of filtrated undiluted human serum (pH 7.2-7.4) and incubated separately for $20 \mathrm{~min}$ (preincubation), $2 \mathrm{~h}$ (to induce germ tubes), $6 \mathrm{~h}$ (to induce pseudohyphae), $18 \mathrm{~h}$ (to induce true hyphae) at $37^{\circ} \mathrm{C}$.
Then, pleomorphic forms were harvested, washed, pelleted and stored as described above. Particular morphotypes were observed under a phase-contrast microscope (Docuval, Carl Zeiss, Germany). To examine cell morphology, the pleomorphic cells were fixed in 2.5\% glutaraldehyde (Serva, Heidelberg, Germany), dehydrated in graded ethanol, critical point dried in $\mathrm{CO}_{2}$, coated with gold and viewed in FEI Quanta 200 Scanning Electron microscope (Czech Republic) (Staniszewska et al., 2011a).

Immunofluorescence microscopy (IFM) Leica TCS SP (Leica, Wetz lar, Germany). The specific antiSap2, anti-Sap3 and anti-Sap6 rabbit polyclonal primary antibodies generated by Chen et al. (2002) were used in the study. Then, each anti-Sap rabbit antibody was separately mixed with Candida cell wall suspension to prevent unspecific labelling. Subsequently, each antibody mixture was centrifuged at $10000 \mathrm{~g}$ for $5 \mathrm{~min}$.

For immunofluorescence staining of Saps the cryosection (Frigocut, model 2700, Reichert-Jung) of pleomorphic forms were blocked with donkey serum (1:20; Merck \& Kollegen, Ochsenhausen, Germany) and incubated with anti-Sap polyclonal rabbit antibodies (1:100), followed by positive human Candida serum (1:60; Merck \& Kollegen, Ochsenhausen, Germany). Antibodies were directed against Sap1-3 and Sap4-6. Samples were then incubated with donkey-anti-rabbit Cy5 (1:500; Merck \& Kollegen, Ochsenhausen, Germany) and donkey-anti-human serum Cy3 (1:500; Merck \& Kollegen, Ochsenhausen, Germany), respectively. This was followed by subsequent nucleus staining with Yopro (1:2000; Invitrogen, Karlsruhe, Germany).

Immunoelectron microscopy (IEM). Electron microscopy and postembedding immunogold labelling of sections of pleomorphic forms were performed as described by Schaller et al. (1998; 1999). In brief, each pellet was fixed in periodate-lysine-paraformaldehyde (PLP) and after embedding in Lowicryl K4M, the blocks were cut using an ultramicrotome (Ultracut; Reichert, Vienna Austria). Ultrathin sections $(30 \mathrm{~nm})$ were mounted on formvar-coated (Serva, Heidelberg, Germany) nickel or cooper grids (Stork Veco, Eerbeek, Netherlands) and incubated with anti-Sap polyclonal rabbit antibodies, directed against Sap1 to Sap3 or against Sap4 to Sap6 followed by $10 \mathrm{~nm}$ or $5 \mathrm{~nm}$-goldconjugated goat-anti-rabbit IgG (Dianova, Hamburg, Germany). In control samples, the primary antibody was omitted. For examination of Sap immunogold labelling, the transmission electron microscope Zeiss Libra 120 (Zeiss, Oberkochen, Germany) operating at $80 \mathrm{kV}$ was used. Evaluation of data obtained from 250 randomly chosen cells was done by determining the intensity of staining with gold particles using a plus scale ranging from $1(+)$ to $4(++++)$, lack of staining was mark as minus (-). 


\section{Results}

Identification of isolated strain. Colony color of the clinical strain 82 grown on CHROMagar ${ }^{\circledR}$ Candida medium was determined to be light green, which is indicative of C.albicans species. Results of this assay indicated that the strain was beta- $\mathrm{N}$-acetylhexosaminidase positive. It was capable of assimilating trehalose (TRE) after $48 \mathrm{~h}$ and $72 \mathrm{~h}$ of incubation. D-Xylose (XYL), DL-lactate (LAC) and alpha-methyl-D-glucoside (MDG) assimilation was observed after $72 \mathrm{~h}$ of incubation. It utilized sucrose as a carbon source for growth, which is another typical feature of C. albicans. The clinical strain 82 and SC5314 reference strain were phenotypically similar in all experimental system described in this study.

Application of C. albicans specific primers (CALB1, CALB2) allowed detecting the expected product size (273 bp) of C.albicans isolate. Subsequently, DNA of strain 82, ATCC SC5314 strain, excluding C. dubliniensis MYA 581, gave readily a PCR product with CALB primers. Primers used in this study were determined to discriminate between C. albicans and C. dubliniensis (Fig. 1).

Detection of Sap1-3 and Sap4-6 antigens by immunofluorescence and immunoelectron staining techniques. Fractions of pleomorphic forms that were examined for their Saps expression are shown in Fig. 2. For strain 82, $100 \%$ of cells were found to form blastoconidia after $18 \mathrm{~h}$ of incubation in YEPD medium. In undiluted human serum, germ tube formation was observed at $2 \mathrm{~h}$ induction and approached $100 \%$. Hyphae were formed as pseudohyphae (chains of elongated blastoconidial cells) at $6 \mathrm{~h}$ induction, with addition of budding blastoconidial cells and uniformly elongated the hyphal cells. True hyphal forms appeared

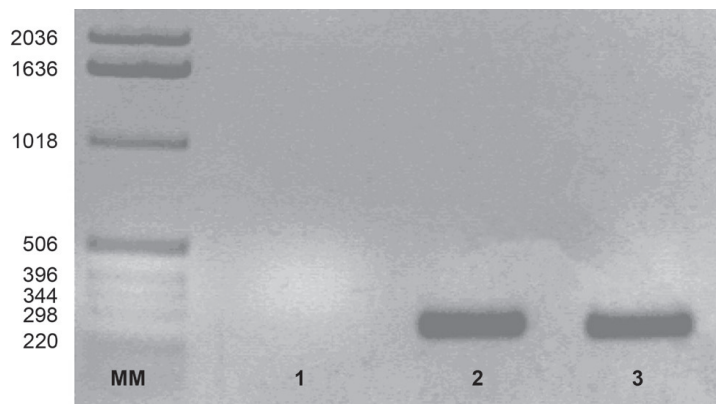

Fig. 1. Candida albicans identification based on PCR amplification of the 5.8S rDNA gene fragment using the CALB1 and CALB2 primers.

(MM) Molecular marker mass; (lane 1) analysis of C. dubliniensis ATCC MYA 581 showed absence of PCR product size (273 bp); (lane 2) PCR product size (273 bp) of C. albicans ATCC 5314; (lane 3) PCR product size (273 bp) of C. albicans clinical strain 82 . PCR products were separated on an agarose gel $(0.8 \%)$ and stained with ethidium bromide.

as homogeneous fraction after incubation for $18 \mathrm{~h}$ in serum. No differences were observed between the clinical strain 82 and SC 5314 reference strain (data not shown) in the ability to form pleomorphic cells.

IFM and IEM were carried out for intracellular detection of Sap1-3 and Sap4-6 in C. albicans pleomorphic cells grown in Sap-inductive human serum and Sap non-inductive media - YEPD. Yeast cells cultivated in YEPD medium for $18 \mathrm{~h}$ as well as cells transferred to undiluted human serum for 20 min showed a lack of blue fluorescence protein of Sap1-3 and Sap4-6 expressing signal. After $2 \mathrm{~h}$ of incubation in Sap-inductive undiluted human serum, Sap labelling became more distinct. Analysis of the different pleomorphic forms cultivated in vitro demonstrated almost similar results for all tested Sap antigens (Table II).

Table II

Expression of aspartic protease (Sap) isoenzymes by pleomorphic forms of Candida albicans

\begin{tabular}{|l|c|c|c|c|c|c|c|c|}
\hline \multirow{2}{*}{$\begin{array}{c}\text { Pleomorphic } \\
\text { cells }\end{array}$} & \multicolumn{3}{|c|}{$\begin{array}{c}\text { Immunogold labelling intensity } \\
\text { (immunoelectron microscopy) }\end{array}$} & \multicolumn{2}{c|}{$\begin{array}{c}\text { Immofluorescence labelling intensity } \\
\text { (fluorescence microscopy) }\end{array}$} \\
\cline { 2 - 9 } & \multicolumn{2}{|c|}{ Sap1-3 } & \multicolumn{2}{c|}{ Sap4-6 } & \multicolumn{2}{c|}{ Sap1-3 } & \multicolumn{2}{c|}{ Sap4-6 } \\
\hline Blastoconidia $^{1}$ & - & $22^{\mathrm{N}}$ & - & $10^{\mathrm{N}}$ & - & $4^{\mathrm{N}}$ & - & $4_{1}^{\mathrm{N}}$ \\
\hline Blastoconidia $^{2}$ & + & 12 & + & 13 & + & 5 & + & 2 \\
\hline Germ tube $^{3}$ & ++ & 29 & +++ & 13 & ++ & 5 & +++ & 5 \\
\hline Pseudohyphae $^{4}$ & ++++ & 30 & +++ & 15 & ++++ & 7 & +++ & 2 \\
\hline True hyphae $^{5}$ & ++++ & 24 & +++ & 36 & ++++ & 8 & +++ & 4 \\
\hline
\end{tabular}

${ }^{1}$ blastoconidia cultivated in YEPD medium ( $\left.\mathrm{pH} 5.7\right)$ for $18 \mathrm{~h}$ at $30^{\circ} \mathrm{C}$

${ }^{2}$ blastoconidia transferred to undiluted human serum ( $\left.\mathrm{pH} 7.2-7.4\right)$ for $20 \mathrm{~min}$ at $37^{\circ} \mathrm{C}$

${ }^{3}$ germ tubes grown in human serum for $2 \mathrm{~h}$ at $37^{\circ} \mathrm{C}$

${ }^{4}$ pseudohyphae grown in human serum for $6 \mathrm{~h}$ at $37^{\circ} \mathrm{C}$

${ }^{5}$ true hyphae grown in human serum for $18 \mathrm{~h}$ at $37^{\circ} \mathrm{C}$

${ }^{N}$ number of analyzed cells

${ }_{1}^{\mathrm{N}}$ number of analyzed images

- lack of Sap immunogold or immunofluorescence staining; from + to ++++ the intensity of Sap

staining with gold particles or immunofluorescence. Cell and images were observed by three persons

independently. The experiment repeated three times gave similar results. 

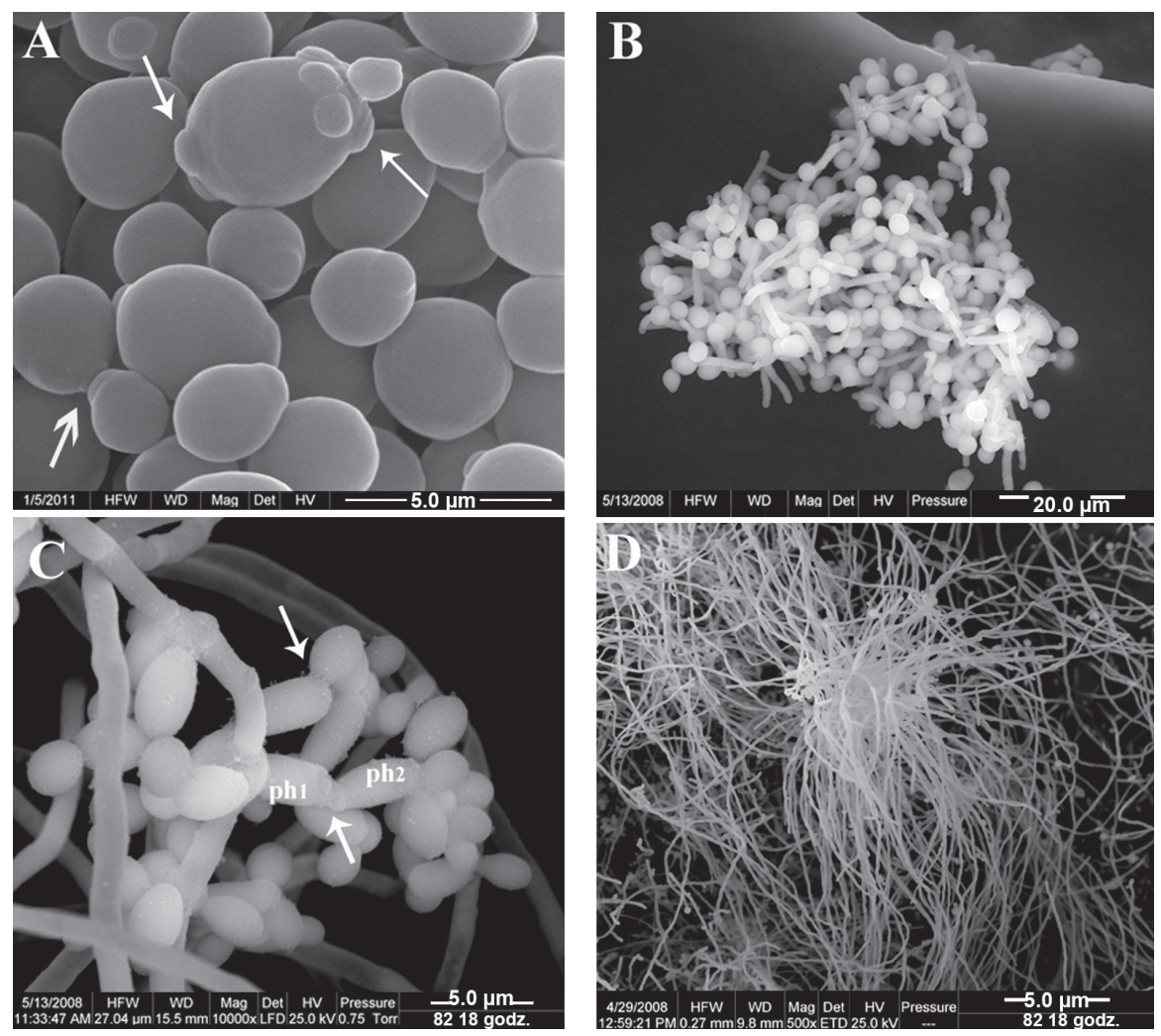

Fig. 2. Candida albicans pleomorphic forms. (A) Blastoconidial cells incubated at $30^{\circ} \mathrm{C}$ for $18 \mathrm{~h}$ in YEPD medium.

Oval-shaped blastoconidial cells exhibiting bipolarly-located bud scars (arrows). Fragile blastoconidial septa are seen (open arrow). Blastoconidial poles are the privileged budding areas. (B) In undiluted human serum blastoconidial cells undergo the process of unipolar germination. After $2 \mathrm{~h}$ of incubation germ tube forms were abundantly observed. (C) $6 \mathrm{~h}$ of cultivation in undiluted human serum at $37^{\circ} \mathrm{C}$. A mixture of pseudohyphae and true hyphae, pseudohyphae forms are visible as chains of elongated blastoconidial cells $\left(\mathrm{ph}_{1}, \mathrm{ph}_{2}\right)$. Fragile septa junctions are typical for pseudohyphal forms (arrows). (D) True hyphae grown for $18 \mathrm{~h}$. Uniformly elongated true hyphal forms exhibit lack of constrictions at the solid septum. Scanning electron micrographs

The results obtained for Sap1-3 (Fig. 3) express nearly similar data obtained for remaining proteins i.e., Sap4-6. The increasing immunoreactivity of Sap1-3 and Sap4-6 was seen in germ tubes, pseudohyphae and true hyphae. On the other hand, there was more intensive Sap1-3 labelling than Sap4-6 in germ tubes, pseudohyphae and true hyphae. Lack of blue fluorescence protein expressing signal was seen in the control without antiSap rabbit polyclonal antibodies.

Sap1-3 and Sap4-6 immunoreactivity results obtained for IEM were similar as described for IFM studies (Table II). Sap immunogold labelling was positive for all pleomorphic cells incubated in human serum for 2 , 6 and $18 \mathrm{~h}$ at $30^{\circ} \mathrm{C}$. In contrast, isoenzymes were below the detection level (estimated as minus -) in all blastoconidial cells grown in YEPD medium for $18 \mathrm{~h}$. Sap1-3 and Sap4-6 were found to be active at a neutral $\mathrm{pH}$ in Sap-inductive medium.

Immunogold labelling showed that in pleomorphic forms Sap localizes mainly in the cell wall and in the cytoplasm. Labelling with Sap antibodies directed against Sap1-3 or Sap4-6 demonstrated lack of reactivity in blastoconidial cells cultivated in YEPD medium and intensive immunoreactivity in cells grown in Sap-inductive medium (human serum). In pleomorphic forms grown in Sap-inductive medium, intensive labelling was observed, often seen as vesicles-associated gold particles. A correlation between germination and Sap1-3 and Sap4-6 expression was demonstrated. Control experiments without polyclonal antibodies showed a complete absence of immunogold labelling with Sap1-3 or Sap4-6. The intensity of Sap1-3 gold particles immunoreactivity (Fig. 4.) bears higher immunogold labelling in germ tubes, pseudohyphae and true hyphae compared with Sap4-6 (Table II). No evidence of gold particles in control cells (without polyclonal rabbit antibodies) was observed. Strain 82 and SC5314 reference strain (data not shown) showed similar Sap1-6 expression in experimental system described in this study. 

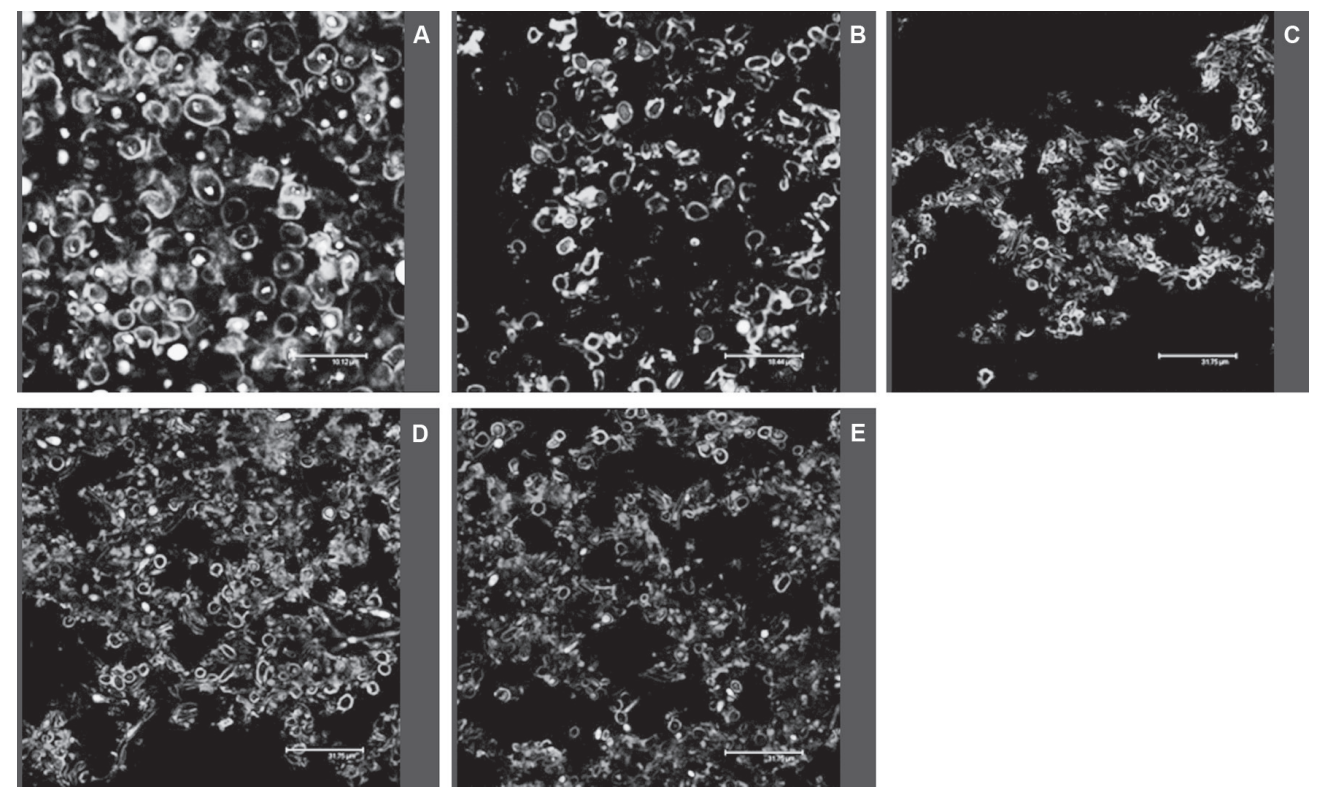

Fig. 3. Visual estimation of Sap1-3 immunolabelling in pleomorphic forms of Candida albicans.

(A) Blastoconidial cells incubated in YEPD (yeast extract-peptone-glucose, YEPD-grown blastoconidial cells) at $30^{\circ} \mathrm{C}$ for $18 \mathrm{~h}$, $(-)$ lack of blue fluorescence of Sap1-3 expressing signal. (B) YEPD-grown blastoconidial cells incubated in undiluted human serum for 20 min, (+) weak Sap1-3 immunoreactivity. (C) Germ tube forms developed from YEPD-grown blastoconidial cells by incubation in undiluted human serum for $2 \mathrm{~h}$ at $37^{\circ} \mathrm{C}$, $(++)$ increased content of Sap1-3. (D) Pseudohyphae developed from YEPD-grown blastoconidial cells by incubation in undiluted human serum for $6 \mathrm{~h}$ at $37^{\circ} \mathrm{C},(++++)$ very high content of Sap1-3. (E) True hyphae developed from YEPD-blastoconidial cells by incubation in undiluted human serum for $18 \mathrm{~h}$ at $37^{\circ} \mathrm{C},(++++)$ very high immunoreactivity of Sap1-3. The immunoreactivity of Sap4-6 was of low intensity at (+++) compared with Sap1-3 in germ tubes, pseudohyphae or true hyphae (Table II)

\section{Discussion}

In this study, the expression of Sap1-6 during C. albicans morphogenesis in undiluted human serum was evaluated. Our data indicate that (1) Sap1-3 and Sap4-6 are the isoenzymes whose expression was observed in germ tubes, pseudohyphae and true hyphae of C. albicans (2) Sap1-3 antigens expression was significantly raised during hyphae formation compared with Sap4-6.

Recent studies (Taylor et al., 2000; Leinberger et al., 2005; Okawa et al., 2007) demonstrated that conventional biochemical tests can misidentify clinical isolates. That is why, in this study, sequence analysis of the $5.8 \mathrm{rDNA}$ region amplified by using the species-specific primer pair (CALB1 CALB2) (Luo and Mitchell, 2002) confirmed that the examined isolate belongs to the C. albicans. In our study, identification of the clinical isolate (strain 82 ) based on genotypic differences confirmed results obtained through phenotypic studies.

Many authors (Lermann and Morschhäuser, 2008; Naglik et al., 2008; Gropp et al., 2009; Dalle et al., 2010), included the reference strain SC5314 and its mutants in studying the roles of secreted Sap hydrolases in the pathogenesis process in humans. We selected the clinical isolate in purpose in view of inconciliable results referring to strain SC5314, which are presented below.
In this study, we compared Saps expression profile of pleomorphic forms of the C.albicans clinical isolate recovered from blood samples as well as SC5314, which was similar (data not shown).

Taylor et al. (2000) showed that C.albicans strain SC5314 well known from animal experiments is a poor colonizer and invader of mammalian epithelia. On the contrary, it was established (Schaller et al., 2000; Felk et al., 2002; Dalle et al., 2010), that this strain was able to invade the host tissues, which was followed by systemic dissemination, as well as it caused damage in an in vitro model. It may be said that the virulence (in view of the place of recovering) of the clinical isolate and the reference strain is comparable; both strains are virulent by intravenous challenge. The clinical strain was chosen because it caused candidaemia in the patient, proving that it develops virulence factors.

Previously, we demonstrated (Staniszewska et al., 2011a) that the clinical isolate showed virulence determinants, it produced germ tubes, pseudohyphae, and true hyphae in undiluted human serum. Furthermore, strain 82 showed distinct differences in activity profiles of hydrolytic enzymes between hyphae and blastoconidia by using the api ${ }^{\oplus} Z$ YM test (Staniszewska et al., 2011b).

In the current work, the antibodies generated by Chen et al. (2002) were used. The authors highlighted 

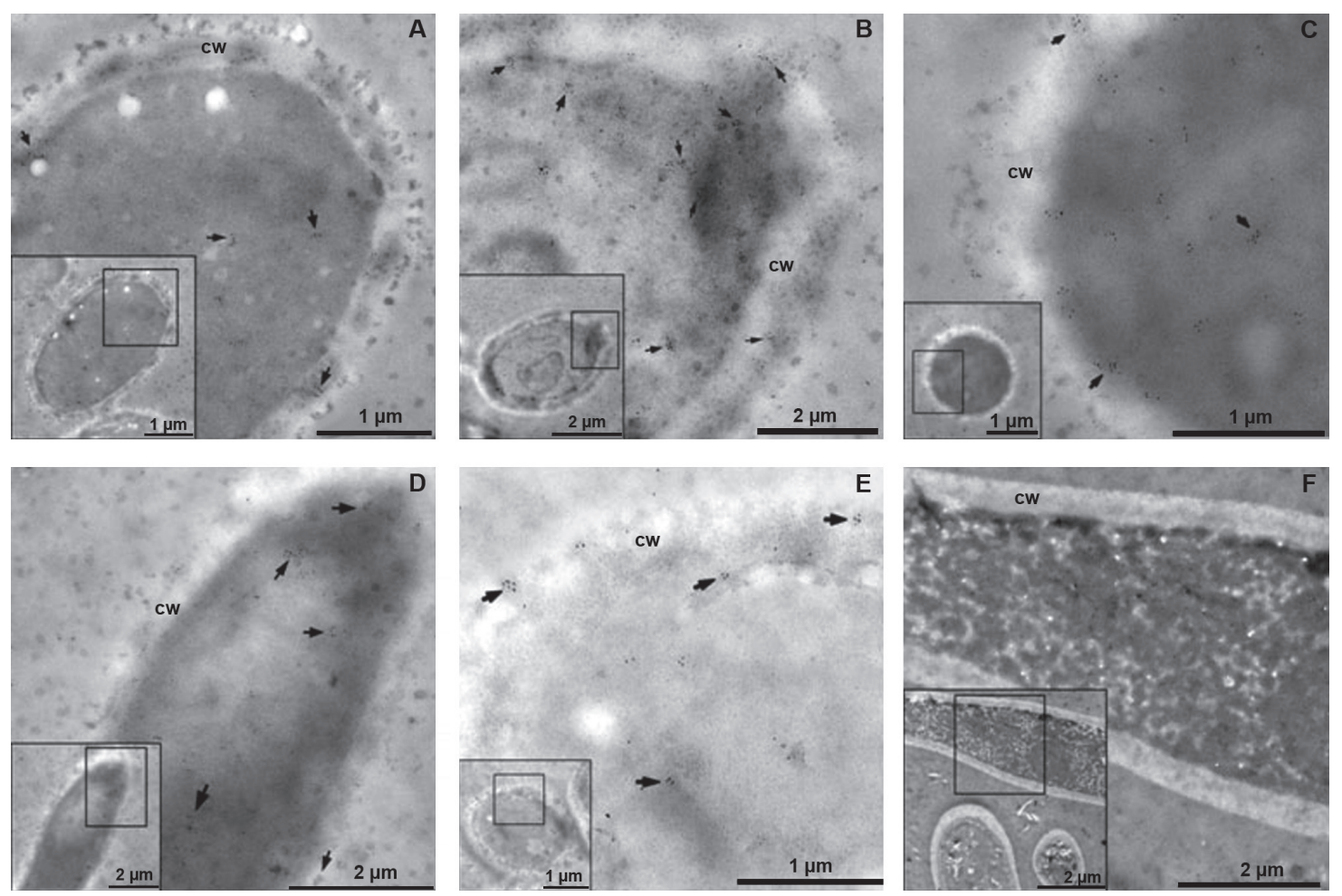

Fig. 4. Immunoelectron microscopy (IEM).

Detection of Sap1-3 in pleomorphic cells of Candida albicans using polyclonal rabbit anti-Sap2 serum and goat-anti-rabbit IgG conjugated to $5 \mathrm{~nm}$ gold particles. (A) Cells cultivated in Sap non-inductive medium YEPD and (B-E) in Sap-inductive undiluted human serum for (B) 20 min, (C) $2 \mathrm{~h}$, (D) $6 \mathrm{~h}$ and (E) $18 \mathrm{~h}$. (A) For blastoconidial cells, the gold particle labelling intensity is evaluated as (-). The gold labelling was not visible in the cytoplasm neither cell wall. (B) Blastoconidial cells cultivated for $20 \mathrm{~min}$ in human serum. The gold particle labelling density is estimated as (+). In comparison to the cell wall (cw), labelling is seen mainly in the cytoplasm (arrows). (C) Germ tube forms. The gold particle labelling density is estimated as (++). Labelling is seen mainly in the cell wall (cw) (arrow). (D) Pseudohyphae. Note the cytoplasm-located clusters of the enzyme marker surrounded by a membrane-like structure (arrows). (E) True hyphae. In comparison to the cytoplasm, labelling is seen mainly in the cell wall (arrow). Enhanced clusters of gold particles in the cell wall are seen. The gold particle labelling density is estimated as (++++). (F) The immunoreactivity of Sap4-6 was less intensive compared with that of Sap1-3 (Table II)

the difficulty with generating specific and sensitive antibodies against each Sap. It was mentioned (Chen et al., 2002) that antibodies against Sap3 showed cross reactivity with Sap2 or Sap4. The cross reactivity of antiSap3 might have affected results obtained in the present study. That is why in our study, additionally anti-Sap2 and anti-Sap6 were used which reacted specifically with Sap1-3 or Sap4-6, respectively (Chen et al., 2002).

The immunofluorescence microscopy studies revealed that the pattern of enzyme expression in blastoconidia grown in YEPD medium differs significantly from other C. albicans forms cultivated in the human serum, possibly due to the fact that YEPD medium contains no suitable substrate for Sap. Higher level of Sap1-6 expression was correlated with the course of germination process and germ tubes, pseudohyphae and true hyphae appearance during incubation blastoconidial cells respectively for 2, 6 and 18 hours in human serum. Analysis using microscopy techniques determine that
Sap expression profiles demonstrate significant differences between particular pleomorphic forms grown in human serum. Sap1-3 expression gradually increased in cells during germination and was much more intensive than Sap4-6. A previous report showed (Hube et al., 1994) that deletion of SAP4-6 did not result in differences in hyphae formation both in vitro and in vivo.

Moreover, Felk etal. (2002) showed that SAP4-6 expression is associated with, but not required for hyphal morphology. Our findings are in line with previous data (Felk et al., 2002), showing that Sap4-6 expression is related with germination process. Additionally, we showed that Sap4-6 are expressed in each morphotype (including blastoconidial cells) under human serum influence.

These results were consistent with the in vivo expression pattern (Staib et al., 2001) and suggested that expression of Sap1-6 proteins is regulated by factors that also regulate C.albicans morphology in human serum. Yet, information on secretion of particular Sap 
isoenzymes by C. albicans germ tubes and pseudohyphae is still missing in the literature. In our studySap1-6 expression was observed in both morphotypes (germ tubes; pseudohyphae).

Our data allow postulating that there is a correlation between human serum induced hyphae growth in vitro and expression of Sap1-6. Here, we showed that the presence of high level of Sap1-3 expression throughout 18-h-incubation in human serum supports the view that Sap1-3 are probably key proteases that promote cell growth and may be dependent on morphology. Although Sap1-3 expression level was higher than Sap4-6, the latter were consistently detected in germ tubes, pseudohyphae and true hyphae at steady levels, which may also support a contributory role of Sap4-6 in C. albicans cell growth and fitness. Our observation is not in line with results published previously (Correia et al., 2010), which suggested that yeast growth may be protease independent when $C$. albicans cells were delivered directly into the bloodstream. On the contrary, Gropp et al. (2009) and Staib et al. (2001) showed that Sap2 is essential for growth when the protein is the only nitrogen source. Another support for our findings may be the previous report (Gropp et al., 2009) showing the strong complement inhibitory activity of Sap 1-3 in human plasma. In the present study, it was shown that the Sap1-3 expression was highly induced in C.albicans hyphal cells upon host body fluid (serum) influence suggesting that also in vivo each of the three Sap proteins may contribute to blood infection, complement inactivation and immune evasion (Gropp et al., 2009). Here, we have provided evidence that the human serum plays a important role in hyphae formation and Sap1-3 expression. However, more investigations about the expression of SAP1-3 as well as SAP4-6 under human serum influence by using RT-PCR are going to be done.

In the current study, increasing Sap1-3 and Sap4-6 expression was detected during hyphae formation induced by shift of temperature (from $30^{\circ} \mathrm{C}$ to $37^{\circ} \mathrm{C}$ ) and $\mathrm{pH}$ (from 5.7 to 7.2 ) in human serum. The same results were obtained for another clinical isolate (Taylor et al., 2000) as well as SC5314 reference strain (data not shown). We did not observe differences between C. albicans strains due to $\mathrm{pH}$ changes. There was no Sap1-3 or Sap4-6 activity in yeast cells grown in medium at $\mathrm{pH}$ 5.7, while germ tubes, pseudohyphae and true hyphae expressed these isoenzymes at a neutral $\mathrm{pH}(7.2-7.4)$. These characteristics may indicate the ability of C. albicans to survive and cause infection in a variety of host tissues.

The results obtained for the expression pattern of the immunofluorescence study were confirmed by immunoelectron microscopy studies (IEM). The use of antibodies raised against Sap1-3 or Sap4-6 made it possible to determine the precise location of these proteins in the pleomorphic forms that have been precultured in human serum. Sap proteins were detected inside the cytoplasm and within the cell wall of blastoconidia, germ tubes, pseudo- and true hyphae forms, but not in the surrounding of the cell wall, which was confirmed by the negative control (non-antigens in the surrounding of the cell wall). The Sap1-3 and Sap4-6 were observed to be organized in groups and packed with the vesicles localized in the cytoplasm. The results of our study are in line with those of Stringaro et al. (1997) demonstrating that during murine vaginitis Sap antigen is located within the cell wall of hyphal cells. Similar results were observed in the in vitro model of experimental oral candidiasis (Stringaro et al., 1997) and reconstituted human epidermis (Schaller et al., 2000).

Our studies may support the data of Brown (2002) that both blastoconidia and filamentous forms of C. albicans are pathogenic and both contribute to different stages in the establishment and progress of the infection. Sap1-6 proteins tested in the above-mentioned study were determined to be expressed in pleomorphic forms during incubation in human serum which mimics in vivo conditions encountered during systemic blood infections. These data may indicate an important role of Sap1-6 proteins during blood infections and immune evasion (Hornbach et al., 2009). We therefore conclude that there is a correlation between the increased expression of Sap1-6 proteins and germ tubes, pseudohyphae and true hyphae formation.

\section{Acknowledgement}

Martin Schaller was supported by the Deutsche Forschungsgemeinschaft (Sch 897/3, SFB773 Z2, graduate college 685), the BMBF (MedSys 0315409B) and by a NIDCR grant R01DE017514-01.

Monika Staniszewska and Wiesław Kurzątkowski were supported by grant N N404 113639 from the Ministry of Science and Higher Education.

We thank Birgit Fehrenbacher, Renate Nordin, Helga Möller and Hannelore Bischof, Univer-sity of Tübingen, for excellent technical assistance.

We thank Prof. D.D. Dzierżanowska-Madalińska for providing C. albicans clinical isolate.

\section{Literature}

Abegg M.A., R. Lucietto, P.V.G. Alabarse, M.F.A. Mendes and M.S. Benfato. 2011. Differential Resistance to oxidants and production of hydrolytic enzymes in Candida albicans. Mycopathologia. 171: $35-41$

Amberg D.C. and D.J. Burke. 2005. Yeast DNA isolation, techniques and protocols 3, p.17. In: Amberg D.C. and D.J. Burke (eds.), Methods in yeast genetics. Cold Spring Harbor Laboratory Press, Cold Spring Harbor.

Argimón S., J.A. Wishart, R. Leng, S. Macaskill, A. Mavor, T. Alexandris, S. Nicholls, A.W. Knight, B. Enjalbert, R. Walmsley, F.C. Odds, N.A.R. Gow and A.J. Brown. 2007. Developmental regulation of an adhesin gene during cellular morphogenesis in the fungal pathogen Candida albicans. Eukaryotic Cell. 6: 682-692. 
Barnett J.A. 2008. A history of research on yeasts 12: medical yeasts part I, Candida albicans. Yeast 25: 385-417.

Brown A.J.P. 2002. Expression of growth form-specific factor dur ing morphogenesis in Candida albicans, pp. 87-93. In: Calderone R.A. (eds.), Candida and candidiasis, ASM Press, Washington, DC. Chen Y.C., C.C. Wu, W.L. Chung and F.J.S. Lee. 2002. Differential secretion of Sap4-6 proteins in Candida albicans during hyphae formation. Microbiol. 148: 3743-3754.

Copping V.M.S., C.J. Barelle, B. Hube, N.A.R. Gow, A.J.P. Brown and F. Odds. 2005. Exposure of Candida albicans to antifungal agents affects expression of $S A P 2$ and $S A P 9$ secreted proteinase genes. J. Antimicrob. Chemother. 55: 645-654.

Correia A., U. Lerman, L. Teixeira, F. Cerca, S. Botelho, R.M.G. da Costa, P. Sampaio, F. Gärtner, J. Morshhäuser, M. Vilanova and others. 2010. Limited role of secreted aspartyl proteinases Sap1 to Sap6 in Candida albicans virulence and host immune response in murine hematogenously disseminated candidiasis. Infect. Immun. 78: 4839-4849.

Dalle F., B. Wächter, C. L'Ollivier, G. Holland, N. Bannert, D. Wilson, C. Labruére, A. Bonnin and B. Hube. 2010. Cellular interactions of Candida albicans with human oral epithelial cells and enterocytes. Cell Microbiol. 12: 248-71.

Décanis N., N. Tazi, A. Correia, M. Vilanova and M. Rouabhia. 2011. Farnesol, a fungal quorum-sensing molecule triggers Candida albicans morphological changes by downregulating the expression of different secreted aspartyl proteinase genes. The Open Microbiology Journal. 5: 119-126.

Felk A., M. Kretschmar, A. Albrecht, M. Schaller, S. Beinhauser, T. Nichterlein, D. Sanglard, H.C. Korting, W. Schäfer and B. Hube. 2002. Candida albicans hyphal formation and the expression of the Efg1-regulated proteinases Sap4 to Sap6 are required for the invasion of parenchymal organs. Infect. Immun. 70: 3689-3700.

Fradin Ch., M. Kretschmar, T. Nitchterlein, C. Gaillardin, Ch. d'Enfert and B. Hube. 2003. Stage-specific gene expression of Candida albicans in human blood. Mol. Microbiol. 47: 1523-1543.

Gillum A.M., E.Y. Tsay and D.R. Kirsch. 1984. Isolation of the Candida albicans gene for ortodine-5'-phosphate decarboxylase by complementation of Saccharomyces cerevisiae ura3 and Eschericha coli pyrF mutations. Mol. Gen. Genet. 198: 179-182.

Gow N.A.R. 2002. Cell biology and cell cycle of Candida, pp. 145-158. In: Calderone R.A. (eds.), Candida and Candidiasis, ASM Press, Washington D.C.

Gropp K., L. Schild, S. Schindler, B. Hube, P.F. Zipfel and C. Skerka. 2009. The yeast Candida albicans evades human complement attack by secretion of aspartic proteases. Mol. Microbiol. 47: 465-475.

Hayek P., L. Dib, P. Yazbeck, B. Beyrouthy, R.A. Khalaf. 2010. Characterization of Hwp2, a Candida albicans putative GPI-anchored cell wall protein necessary for invasive growth. Microbiol Res. 165: 250-258.

Hornbach A., A. Heyken, L. Schild, B. Hube, J. Löffler and O. Kurzai. 2009. The glycosylphosphatidylinositol-anchored protease Sap9 modulates the interaction of Candida albicans with human neutrophils. Infect. Immune. 77: 1-9.

Hube B., M. Monod, D.A. Schofield, A.J. Brown and N.A.R. Gow. 1994. Expression of seven members of the gene family encoding secretory aspartic proteinases in Candida albicans. Mol. Microbiol. 14: 87-99.

Hube B. 2004. From commensal to pathogen: stage- and tissuespecific gene expression of Candida albicans. Curr. Opin. Microbiol. 7: 336-341.

Jackson B.E., K.R. Wilhelmus and B. Hube. 2007. The role of secreted aspartyl proteinases in Candida albicans keratitis. IOVS. 48: 3559-3565.
Kumamoto C.A.and M.D. Vinces. 2005a. Alternative Candida albicans lifestyles: Growth on surface. Annu. Rev. Microbiol. 59: 113-130. Kumamoto C.A. and M.D. Vinces. 2005b. Contributions of hyphae and hypha-co-regulated genes to Candida albicans virulence. Annu. Rev. Microbiol. 7: 1546-1554.

Leinberger D.M., U. Schumacher, I.B. Autenrieth and T.T. Bachmann. 2005. Development of a DNA Microarray for Detection and Identification of Fungal Pathogens Involved in Invasive Mycoses. J. Clin. Microbiol. 43: 4943-4953.

Lermann U. and J. Morschhäuser. 2008. Secreted aspartic proteases are not required for invasion of reconstituted human epithelia by Candida albicans. Microbiol. 154: 3281-3295.

Luo G. and T.G. Mitchell. 2002. Rapid identification of pathogenic fungi directly from cultures by using multiplex PCR. J. Clin. Microbiol. 40: 2860-2865.

Monod M., G. Togni, B. Hube, and D. Sanglard. 1994. Multiplicity of genes encoding secreted aspartic proteases in Candida species. Mol. Microbiol. 13: 357-368.

Monod M., Togni, B. Hube, D. Heß, D. Sanglard. 1998. Cloning, sequencing, and expression of two new members of the secreted aspartic proteinase family of Candida albicans. Microbiology. 144: 2731-2737.

Morrison C.J., S.F. Hurst and E. Reiss. 2003. Competitive binding enzyme-linked immunosorbent assay that uses the secreted aspartyl proteinase of Candida albicans as an antigenic marker for diagnosis of disseminated candidiasis. Clin. Diagn. Lab. Immunol. 10: 835-848. Naglik J.R., G. Newport, T.C. White, L.L. Fernandes-Naglik, J.S. Greenspan, D. Greenspan, S.P. Sweet, S.J. Challacombe and N. Agabian. 1999. In vivo analysis of secreted aspartyl proteinases expression in human oral candidiasis. Infect Immun. 67: 2482-2490. Naglik J.R., S.J. Challacombe and B. Hube. 2003. Candida albicans secreted aspartyl proteases in virulence and pathogenesis. Microbiol. Mol. Biol. Rev. 67: 400-428.

Naglik J.R., D. Moyes, J. Makwana, P. Kanzaria, E. Tsichlaki, G. Weindl, A.R. Tappuni, C.A. Roggers, A.J. Woodman, S.J. Challacombe and others. 2008. Quantitative expression of the Candida albicans secreted aspartyl proteinase gene family in human oral and vaginal candidiasis. Microbiol. 154: 3266-3280.

Ness F., V. Prouzet-Mauleon, A. Vieillemard, F. Lefebvre, T Noël, M. Crouzet, F. Doignon and D. Thoraval. 2010. The Candida albicans Rgd1 is a RhoGAP protein involved in the control of filamentous growth. Fungal Genet Biol 47: 1001-1011.

Okawa Y., M. Miiiyauchi, S. Takahashi and H. Kobayashi. 2007. Comparison of pathogenicity of various Candida albicans and C. stellatoidea strains. Biol. Pharm. Bull. 30: 1870-1873.

Raška M., J. Běláková, M. Křupka and E. Weigl. 2007. Candidiasis - do we need to fight or to tolerate the Candida fungus? Folia Microbiol. 52: 297-312.

Schaller M., W. Schafer, C. Korting and B. Hube. 1998. Differential expression of secreted aspartyl proteinases in model of human oral candidiosis and in patient samples from oral cavity. Mol. Microbiol. 29: 605-615.

Schaller M., H.C. Korting, W. Schäfer, J. Bastert, W. Chen and B. Hube. 1999. Secreted aspartic proteinase (Sap) activity contributes to tissue damage in a model of human oral candidiasis. Mol. Microbiol. 34: 169-180.

Schaller M., C. Schackert, H.C. Korting, E. Janusche and B. Hube. 2000. Invasion of Candida albicans correlates with expression of secreted aspartic proteinases during experimental infection of human epidermis. J. Invest. Dermatol. 114: 712-717.

Schaller M., E. Januschke, C. Schackert, B. Woerle and H.C. Korting. 2001. Different isoforms of secreted aspartyl proteinases (Sap) are expressed by Candida albicans during oral and cutaneous candidiosis in vivo. J. Med. Microbiol. 50: 743-747.

Schild L., A. Heyken, P.W.J. de Groot, E. Hiller, M. Mock, C. de Koster, U. Horn, S. Rupp and B. Hube. 2001. Proteolytic cleavage 
of covalently linked cell wall proteins by Candida albicans Sap9 and Sap10. Eukaryot Cell. 10: 98-109.

Staib P., S. Wirsching, A. Strauß and J. Morschhäuser. 2001. Gene regulation and host adaptation mechanisms in Candida albicans. Int. J. Med. Microbiol. 291: 183-188.

Staniszewska M., M. Bondaryk and W. Kurzątkowski. 2011a Morphotypes of Candida albicans. Phase-contrast microscopy. Med. Mycol. 18: 5-10.

Staniszewska M., D. Rabczenko and W. Kurzątkowski. 2011b. Discrimination between the enzymatic activities of Candida albicans pleomorphic forms determined using the api ${ }^{\circledast}$ ZYM test. Mycoses 54: e744-e750. doi: 10.1111/j.1439-0507.2010.02011.x

Stringaro A., P. Crateri, G. Pellegrini, G. Arancia, A. Cassone and F. De Bernardis. 1997. Ultrastructural localization of the secretory aspartyl proteinase in Candida albicans cell wall in vitro and in experimentally infected rat vagina. Mycopathologia 137: 95-105. Sullivan D.J., T.J. Westerneng, K.A. Haynes, D.E. Bennett and D.C. Coleman. 1995. Candida dubliniensis sp. nov.: Phenotypic and molecular characterization of a novel species associated with oral candidosis in HIV-infected individuals. Microbiology 141: 1507-1521.
Taylor B.N., C. Fichtenbaum, M. Saavedra, J. Slavinsky III, R. Swoboda, K. Wozniak, A. Arribas, W. Powderly and P.L. Fidel Jr. 2000. In vivo virulence of Candida albicans isolates causing mucosal infections in people infected with the human immunodeficiency virus. J. Infect. Dis. 182: 955-959.

Taylor B.N., H. Hannemann H., M. Sehnal, A. Biesemeier, A. Schweizer, M. Röllinghoff and K. Schröppel. 2005. Induction of SAP7 correlates with virulence in an intravenous infection model of candidiasis but not in a vaginal infection model in mice. Infect Immun. 73: 7061-7063.

Tongchusak S., V. Brusic and S.C. Chaiyaroj. 2008. Promiscuous T cell epitope prediction of Candida albicans secretory aspartyl proteinase family of proteins. Infect. Genetics Evolution. 8: 467-473.

Whiteway M. and C. Bachewich. 2007. Morphogenesis in Candida albicans. Annu. Rev. Microbiol. 61: 529-553.

Wise M.G., M. Healy, K. Reece, R. Smith, D. Walton, W. Dutch, A. Renwick, J. Huong, S. Young, J. Tarrand and others. 2007. Species identification and strain differentiation of clinical Candida isolates using the DiversiLab system of automated repetitive sequencebased PCR. J. Med. Microbiol. 56: 778-787. 